\title{
Estudantes de medicina veterinária como consumidores de carne suína em Uberlândia, MG
}

$\underline{\text { Ana Carolina Portella Silveira }}{ }^{1^{*}}, \underline{\text { Carolina Magalhães Caires Carvalho }}^{2}, \underline{\text { Paulo Fernando Alves }}$ $\underline{\text { de Freitas }}^{3}$, Carolyn Aboujaoude ${ }^{2}$, Maitê Soares Jordão de Carvalho ${ }^{1}$, Robson Carlos ${\underline{\text { Antunes }^{2}}}^{2}, \underline{\text { Élcio Eduardo de Paula Santana }}{ }^{1}$

${ }^{1}$ Universidade Federal de Uberlândia, Faculdade de Gestão e Negócios, Uberlândia, MG, Brasil

${ }^{2}$ Universidade Federal de Uberlândia, Faculdade de Medicina Veterinária, Uberlândia, MG, Brasil

${ }^{3}$ Médico Veterinário - Mestre em Ciências Veterinárias

Autor para correspondência: anacarolinaportella@gmail.com

RESUMO. Este artigo apresenta uma pesquisa survey sobre o comportamento dos alunos de Medicina Veterinária da Universidade Federal de Uberlândia como consumidor de carne suína, visto que são formadores de opinião acerca do tema para a população em geral. Para avaliar a opinião dos alunos, foi elaborado um questionário com 30 perguntas fechadas, semiabertas e dicotômicas que levaram questões sobre o conhecimento dos entrevistados a respeito da carne suína e suas preferências, definindo seu perfil. Os resultados indicam que apesar de aceitarem bem o produto por seu sabor e preço acessível, os estudantes ainda rejeitam a carne suína baseados em preconceitos e mitos, como condições sanitárias e higiênicas inadequadas na cadeia produtiva da suinocultura e altos índices de gordura e colesterol com risco à saúde dos consumidores. Campanhas de marketing, palestras, eventos científicos e ênfase nas disciplinas dentro do currículo destes alunos devem ser pensadas focando nesse público específico ao longo de todo o curso, pois com as informações corretas, os futuros profissionais ajudarão a disseminar as melhorias do agronegócio neste setor, auxiliando na desmistificação da carne suína, elucidando a população e possivelmente, auxiliando no aumento do seu consumo.

Palavras chave: carne in natura, hábitos de consumo, perfil, suinocultura

\section{Veterinary Medicine students as consumers of pork in Uberlândia, Brazil}

\begin{abstract}
This article presents a survey on the behavior of students of Veterinary Medicine, Federal University of Uberlândia as consumers of pork, since they are opinion leaders on the subject for the general population. To evaluate the students' opinions, we designed a questionnaire with 30 closed questions, which led semi-open and dichotomous questions about the knowledge of respondents about the pork and preferences, setting your profile. The results indicate that although the product is accepted for its taste and affordable price, the students still reject pork-based prejudices and myths, such as sanitation and inadequate hygiene in the production chain of swine and high fat and high cholesterol health risk to consumers. Marketing campaigns, lectures, scientific meetings and focus on subjects within the curriculum of these students should be thought of focusing on this specific audience throughout the course, as with the correct information, future professionals will help spread improvements in the agribusiness sector, assisting in the demystification of pork, elucidating the population and possibly aiding in the increase of its consumption.
\end{abstract}

Key words: pork, consumer, spending habits, profile, swine culture 


\section{Introdução}

O consumo de carne suína em diversas partes do mundo é extremamente elevado, sendo a mais consumida do mundo, representando 39\% (FAO, 2007) de todo o consumo de carne mundial, seguido pela de aves e bovinos (Oliveira, 2006). Entretanto, o Brasil tem na suinocultura sua terceira mais consumida fonte de proteína animal, com 14,6 kg/per capita/ano, sendo $89 \%$ da produção na forma de industrializados (ABPA, 2015).

Apesar dos consumidores brasileiros aprovarem o sabor da carne suína, seu baixo consumo está ligado aos mitos de que a mesma "faz mal e é perigosa para a saúde" e que possui "muita gordura e colesterol" (Bezerra et al., $\underline{2007)}$.

Há algumas décadas, percebida como uma carne "gorda" e "forte", a carne suína vem passando por transformações no seu meio de produção, para proporcionar uma nova imagem aos consumidores. $\mathrm{O}$ incremento tecnológico, o aumento da escala, a especialização e coordenação entre os elos da cadeia são fatores fundamentais, para a agregação na qualidade desejada pelo consumidor final, cada vez mais consciente e informado sobre os aspectos nutricionais e sanitários das carnes (Miele, 2007; Silva et al., 2008).

As necessidades dos consumidores estão em constante mudança e certamente novos padrões surgirão à medida que a renda disponível para produtos de maior conveniência aumente (Silva et al., 2008). Por isso, conhecer o que querem os consumidores e como eles tomam suas decisões sobre a compra e a utilização de produtos é fundamental para que as organizações tenham êxito em seu mercado. A partir deste conhecimento, os empresários podem qualificar seus produtos e serviços, considerando efetivamente os desejos e as necessidades do consumidor e orientando suas ofertas para o mercado (Sheth et al., 2001).

Neste sentido, objetivou-se compreender o comportamento do consumidor de carne suína, a partir do universo dos alunos da Faculdade de Medicina Veterinária (FAMEV) da Universidade Federal de Uberlândia (UFU).

\section{Material e Métodos}

A pesquisa baseou-se na aplicação de questionário anônimo, utilizando a técnica survey, o qual foi respondido por 166 estudantes do curso de Medicina Veterinária da FAMEVUFU. A resposta afirmativa do questionamento sobre o consumo de carne suína foi o principal filtro da pesquisa, de forma que os 16 indivíduos que não eram consumidores ativos da carne suína (não apreciam seu sabor, a consideram muito gordurosa, não consumem carne vermelha, motivos religiosos e ser alérgico a mesma) foram descartados. Sendo assim, foi definida uma amostragem de 150 elementos, dos quais 58,67\% eram mulheres e $41,33 \%$ homens. E $61,33 \%$ na faixa etária de 20 a 29 anos; $32 \%$ com idade até 19 anos; $5,33 \%$ de 30 a 39 anos e $1,33 \%$ de 40 a 49 anos.

As entrevistas foram conduzidas em Uberlândia-MG, nos meses de novembro e dezembro de 2010 e o questionário foi estruturado com 30 questões fechadas, semiabertas e dicotômicas que levantaram questões sobre o conhecimento dos entrevistados a respeito da carne suína e suas preferências, definindo seu perfil. E com um modelo de estratificação social baseado em Mattar (1997), no qual $73,3 \%$ dos entrevistados pertencem ao estrato social $\mathrm{B} ; 16,7 \%$ ao $\mathrm{C} ; 7,3 \%$ ao $\mathrm{A} ; 2,7 \%$ ao $\mathrm{D}$ e nenhum entrevistado ao $\mathrm{E}$. Os dados obtidos foram tabulados e submetidos à análise estatística descritiva, com ênfase na distribuição de frequiências relativas das respostas, por meio do Microsoft Excel.

\section{Resultados e Discussão}

Dos acadêmicos consumidores ativos da carne suína, $68,67 \%$ afirmam consumir mais a bovina; $28,67 \%$ a de frango; $2,0 \%$ a de peixe e $0,67 \%$ a suína (Tabela 1). Couto \& Ferreira (2003) relataram que 50,4\% dos moradores de Patos de Minas-MG preferem a carne bovina, 21,3\% preferem a carne suína, $14,2 \%$ preferem peixes, $13,4 \%$ preferem frango e $0,8 \%$ preferem outras carnes. Eles acreditam que essa diferença possa ser justificada devido à produção suinícola do município. Para Bezerra et al. (2007), a carne bovina assume a liderança, com 47,75\% dos votos, seguida das carnes de frango $(21,75 \%)$, suína $(17,5 \%)$ e, por último, de peixe, com $13,00 \%$ do total.

O sabor é o principal motivo para o consumo de carne bovina seguido do hábito, da praticidade, do preço, da aparência e do valor nutritivo (Gráfico 1). 
Apesar de consumirem a carne suína, 65 dos estudantes disseram come-la menos de uma vez por semana; 41 uma vez por semana; 30 duas vezes por semana; 8 três vezes por semana; 4 quatro vezes por semana; 1 cinco vezes por semana; 1 seis vezes por semana e 1 diariamente (Tabela 2).

Varga (2015) afirma que a frequência de consumo da carne suína em Santa Catarina é a maior do país, uma vez que, o estado tem produção muito significativa possibilitando um alimento fresco e habitual na rotina semanal da maioria dos consumidores, e com preços mais acessíveis.
Os estudiosos parecem ser unânimes ao afirmarem que mesmo com aumento significativo da produção brasileira, com grandes ganhos de produtividade, uma vez que, com aumento de apenas $27,6 \%$ em seu plantel alavancou em $74 \%$ sua produção nos últimos dez anos, a suinocultura brasileira ainda não foi eficaz em atingir grande consumo interno, que embora ainda pequeno, passou de $11,9 \mathrm{~kg}$ em 2004 para 14,6 kg em 2015 (ABPA, 2015), porém mantevese distante do consumo dos países desenvolvidos, como Dinamarca e Espanha, cujas médias de consumo são de 76 e 66 kg/habitante/ano.

Tabela 1. Carne consumida com mais frequência pelos estudantes de Medicina Veterinária - UFU no período de novembro e dezembro de 2010, Uberlândia, MG.

\begin{tabular}{lcc}
\hline Tipos de carne & Consumo $(\%)$ & $\mathrm{N}^{\mathrm{o}}$ de entrevistados \\
\hline Bovina & 68,67 & 103 \\
Frango & 28,67 & 43 \\
Peixe & 2,0 & 4 \\
Suína & 0,67 & 1 \\
\hline Total & 100 & 150 \\
\hline
\end{tabular}

Para eles, esse resultado está intimamente relacionado ao preconceito frente à saúde, devido às doenças relacionadas ao "porco", à falta de praticidade dos cortes, que são em geral volumosos e inadequados ao preparo e com os hábitos dos consumidores que, especialmente orientados pela classe médica e nutricionistas, evita o consumo, pois consideram que esta carne possui muito colesterol. Assim, por não terem sido atingidos por campanhas elucidativas, consomem muita carne bovina, a despeito de seu preço mais elevado, quando comparado com a suína (Couto \& Ferreira, 2003; Raimundo \& Zen, 2010).

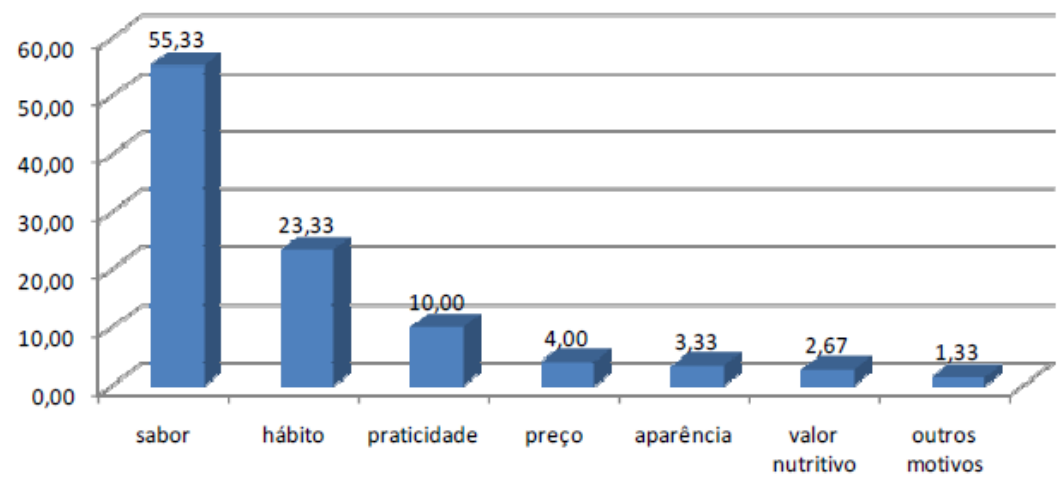

Gráfico 1. Motivos pelos quais, os estudantes de Medicina Veterinária - UFU preferem um tipo de carne em relação a outro, em porcentagem, no período de novembro e dezembro de 2010, Uberlândia-MG.

Dentre os cortes já conhecidos da carne suína, os estudantes afirmaram preferirem o pernil (33,3\%); o lombo (23,3\%); a costela $(21,3 \%)$, alguns não possuem um corte preferido $(14,0 \%) \mathrm{e}$ outros preferem a bisteca (8\%) (Gráfico 2). Segundo Raimundo \& Zen (2010), tendo em 
vista que o quilo do produto em geral custa menos do que o corte mais consumido da carne bovina, o coxão mole, é impossível afirmar que o menor consumo da carne suína por parte dos brasileiros ocorra por razões financeiras. E o que poderia justificar esse comportamento é a relação de cortes disponíveis do animal, ainda pouco adaptados para o tamanho médio das famílias brasileiras, visto que, de acordo com o IBGE, a família brasileira diminuiu de tamanho, passando de 2,4 filhos por família em 1980, para 1,4 filhos, em média, hoje.

Tabela 2. Frequência de consumo da carne suína por parte dos alunos da Medicina Veterinária - UFU no período de novembro e dezembro de 2010, Uberlândia-MG.

\begin{tabular}{lc}
\hline Frequência de consumo & $\%$ de consumidores \\
\hline 1 vez por semana & 43,33 \\
2 vezes por semana & 27,33 \\
3 vezes por semana & 20,00 \\
4 vezes por semana & 5,33 \\
5 vezes por semana & 2,67 \\
6 vezes por semana & 0,67 \\
Diariamente & 0,67 \\
\hline Total & 100 \\
\hline
\end{tabular}

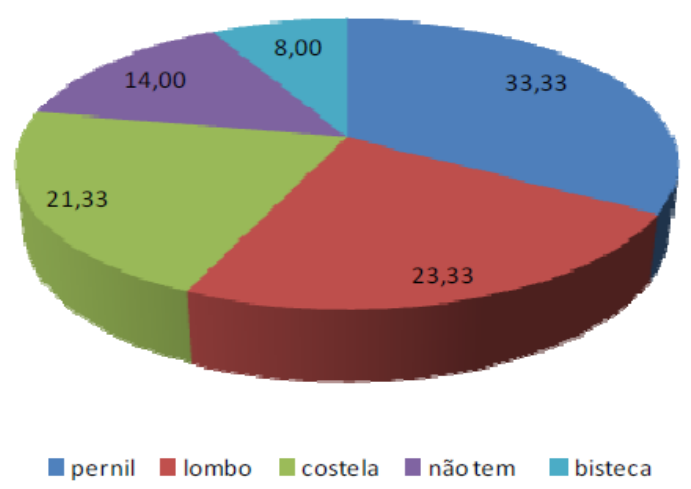

Gráfico 2. Cortes de preferência dos alunos de Medicina Veterinária-UFU, em porcentagem, no período de novembro a dezembro de 2010, Uberlândia-MG.

A nova conjuntura familiar brasileira abre espaço para valorização das carnes prépreparadas e/ou oferecidas em pequenos volumes, bem como de cortes nobres. Dessa forma, ao invés de optar pelo produto embutido, o consumidor poderia escolher cortes como, por exemplo: para strogonoff, medalhão de filé mignon, carne moída com baixo teor de gordura, a picanha (da qual ninguém se declarou consumidor), dentre outros. É possível perceber que os consumidores estão abertos a esses novos cortes da carne suína, visto que quando perguntados, $90 \%$ dos alunos afirmaram que se interessariam em comprar cortes diferenciados da carne suína, como picanha suína, filé mignon, patinho, alcatra, coxão mole, carne moída, etc. e $10 \%$ afirmaram que não comprariam, pois acreditam que o sabor da carne não se altera nos diferentes cortes ou por não terem preferência pela carne suína.

O que mais importa no momento da compra da carne in natura para os estudantes é a qualidade $(48 \%)$, higiene $(24,7 \%)$, a aparência $(16,7 \%)$, preço $(6 \%)$ e finalidade $(4 \%)$. Nenhum entrevistado respondeu a marca. Já quando questionados o que é mais relevante na compra da carne industrializada, 54,0\% também responderam a qualidade, $20,0 \%$ afirmaram a higiene, $13,3 \%$ disseram o preço, $8,7 \%$ a marca e $4 \%$ a finalidade. 
Sobre o valor nutricional da carne suína na atualidade, $66 \%$ dos estudantes responderam não se sentirem bem informados sobre o tema e $34 \%$ acreditam saberem sobre isso. Uma das preocupações dos consumidores é a gordura mostrando que, $44,67 \%$ dos estudantes afirmaram retirar a mesma da carne suína ao consumi-la; $33,33 \%$ o fazem somente em alguns casos e $22 \%$ não o fazem. Raimundo \& Zen (2010) afirmaram que muitos consumidores desejavam que a carne suína fosse mais magra para que pudessem consumi-la com mais frequência, reforçando a ideia da transmissão errônea de informação ao consumidor e da necessidade do setor de organizar esforços cada vez maiores para conscientizar a população do suíno que hoje chega ao varejo.

Ao questionar, qual o momento em que mais consomem a carne suína in natura, os estudantes afirmaram ser durante o almoço $(56,7 \%)$, em churrascos $(22,7 \%)$, em ocasiões festivas $(12,7 \%)$, no jantar $(6,7 \%)$ e em lanches $(1,3 \%)$. Enquanto que, em relação à carne suína industrializada $39,3 \%$ responderam consumi-la preferencialmente em lanches, $30 \%$ em almoços, $14 \%$ em ocasiões festivas, $12,7 \%$ em churrascos e $4 \%$ em jantares. Couto \& Ferreira (2003) observaram que o consumo da carne suína é afetado expressivamente por datas específicas no ano. Nesse sentido $92,7 \%$ dos consumidores entrevistados declararam ampliar seu consumo nas festas de fim de ano. Esse fato acaba por gerar efeitos encadeados via aumento de preços e na renda dos suinocultores.

Quanto ao local em que compram o produto, $59,33 \%$ responderam que o fazem em supermercados, $36 \%$ em açougues e 4,7\% compram diretamente do produtor. Bezerra et al. (2007); Murata et al. (2002); Cavalcante Neto (2003) e Dutra Junior et al. (2003) também encontraram o supermercado como local de preferência de compra da carne suína e seus derivados. De acordo com Marchi (2001) e Carvalho (2007), esse hábito consiste numa tendência cada vez mais consolidada no varejo brasileiro. Por outro lado, alguns consumidores afirmaram optar pela compra no supermercado apenas esporadicamente, pois, no geral, preferem o açougue pela maior variedade de carnes, por confiarem no estabelecimento, e também por acreditarem que a carne seja mais fresca. Destes, a maior parte são mulheres, as quais se dizem preocupadas com a qualidade do alimento que servem à família, colocando a rapidez em segundo plano.

Em relação ao preço da carne in natura e industrializada, grande parte dos estudantes considera acessível (Tabela 3). Já alguns consumidores afirmaram a Raimundo \& Zen (2010) que, de forma geral, acreditam que a carne esteja cara, mesmo que a de suíno ainda seja mais barato que a bovina, ambas estão acima dos patamares considerados comuns, ou seja, o que se pagava "há um tempo".

Tabela 3. Opinião dos alunos de Medicina Veterinária-UFU em relação ao preço da carne suína in natura e industrializada, no período de novembro e dezembro de 2010, Uberlândia-MG

\begin{tabular}{lcccc}
\hline Preço & \multicolumn{2}{c}{ Carne in natura } & \multicolumn{2}{c}{ Carne industrializada } \\
\hline Acessível & 131 & $87,33 \%$ & 116 & $77,33 \%$ \\
Cara & 11 & $7,33 \%$ & 24 & $16 \%$ \\
Barata & 8 & $5,33 \%$ & 10 & $6,67 \%$ \\
\hline Total & 150 & $100 \%$ & 150 & $100 \%$ \\
\hline
\end{tabular}

Raimundo \& Zen (2010) citam que a Teoria do Consumidor explica que a demanda por um bem de consumo varia diretamente com seu preço, com o preço dos bens substitutos, com a satisfação que ele proporciona ao consumidor, e com a renda deste, sem falar em aspectos socioeconômicos como comodidade e status. Ao trabalhar sobre o desejo de consumo que envolve a carne suína, podem ser determinados aprimoramentos no produto final, de forma a aumentar a competitividade do produto frente às carnes concorrentes (Kinpara, 1995).

Segundo Couto \& Ferreira (2003), do ponto de vista das casas de carne, o preço da compra do suíno é determinante na colocação da venda ou não desse produto, conforme declaração de 39\% dos gerentes ou proprietários das casas de carne entrevistados. Afirmam, ainda que, pela pesquisa 
realizada verifica-se que a percepção do consumidor, bem como das casas de carne e supermercados, de que o preço da carne suína é menor do que a bovina, pode ser considerado como um fator a ser explorado e de potencial de ampliação do consumo.

Dos respondentes, $73,3 \%$ não deixam de consumir a carne suína em situações específicas, $18 \%$ não a consomem em casos de recuperação de cirurgias e $8,7 \%$ não a ingerem quando estão doentes. Esse mito é baseado no fato de que comidas gordurosas podem prejudicar a cicatrização de feridas e por este motivo, médicos indicam que a carne suína não deve ser consumida, por ainda acreditarem que esta é muito gordurosa. De acordo com Bezerra et al.,(2007), um estudo com diversos tipos de carnes, derrubou o mito de que a carne suína possuía mais colesterol que as carnes de bovino e frango.

Quanto ao conhecimento sobre cisticercose, a maioria $(72,67 \%)$ afirma conhecer sobre a doença. Com isso, $70 \%$ alunos afirmaram que o suíno é capaz de transmitir a cisticercose para o homem, 33,33\% acreditam que o bovino também é capaz de fazê-lo, 10,96\% afirmaram que o próprio homem é quem transmite a cisticercose para o suíno, 6,85 associaram os caprinos e ovinos como transmissores dessa doença, 2,74\% responderam que os peixes também são capazes de transmitir a cisticercose ao homem e 2,28\% creem que as aves também são transmissoras da enfermidade. Para Farias et al. (2012) ficou claramente demonstrado que os consumidores na sua maioria, ainda desconhecem temas extremamente relevantes nos dias atuais, como a cisticercose. Existem outras maneiras de contrair a cisticercose, como por exemplo, por meio de alimentos ou água contaminada com fezes de humanos portadores da tênia (Pedroso-de-Paiva, 2007). Bezerra et al. (2007) constataram o total desconhecimento da população em relação à cisticercose, pois sabe-se que é impossível o homem adquirir essa doença via carne e que, ao comer carne crua ou mal passada dos suínos e bovinos, que contenha as larvas das tênia (cisticercos), o homem passa a desenvolver teníase e não cisticercose.

Sobre propagandas de incentivo a carne suína, $66 \%$ dos estudantes nunca viram, enquanto que, $34 \%$ já viram. Na pesquisa de Couto \& Ferreira (2003), em Patos de Minas-MG, notou-se uma disposição de $90,2 \%$ dos comerciantes em fazer promoções conjuntas com os suinocultores a fim de divulgá-la. Estas campanhas tornam-se necessárias, pois os 92,3\% dos consumidores acham as outras carnes mais saudáveis que a suína e, 27,4\% deles ainda pensam que os suínos consomem restos de comida (Couto \& Ferreira, 2003).

Nos últimos anos, notou-se um esforço por parte da Associação Brasileira de Criadores de Suínos (ABCS) para proporcionar, ao consumidor brasileiro, informação que favoreça o consumo da carne suína (Raimundo \& Zen, 2010). De acordo com Couto \& Ferreira (2003) os esforços da ABCS por meio de campanhas de marketing promovendo a qualidade da carne suína e estimulando o consumo, tem obtido um aumento no consumo per capita/ano em torno de $7,88 \%$, enquanto que, no mundo a taxa de crescimento anual é de 2,5\%. A colocação de cortes em embalagens adequadas, com uma oferta constante e preços acessíveis é uma das opções para o aumento do consumo da carne suína.

Dos respondentes, $38 \%$ não têm dúvidas sobre a cadeia suinícola, $22 \%$ gostariam de saber mais sobre a qualidade nutricional da carne suína, $17,3 \%$ tem dúvidas sobre a qualidade sanitária deste produto, $17,3 \%$ sobre como são produzidos os embutidos, 4,67\% não sabe como se dá a criação dos suínos e um aluno afirma não conhecer nada sobre o processo.

Dos entrevistados, $50,00 \%$ acreditam que os animais são criados em boas condições higiênicas e sanitárias, $27,33 \%$ afirmam que essas condições são regulares, $10 \%$ creem que são ótimas, 9,33\% não souberam responder e 3,3\% dizem serem péssimas. Diferentes dos resultados encontrados por Bezerra et al. (2007), nos quais $47,25 \%$ das pessoas entrevistadas acreditavam que os suínos eram criados em péssimas condições de higiene. Já 28\% afirmaram que eles são criados em razoáveis condições de higiene e $24,25 \%$ não sabem como e em quais condições isso ocorre. Essa diferença pode ser justificada pelo fato dos alunos de Medicina Veterinária terem acesso a mais informações sobre a cadeia produtiva da carne suína que os consumidores em geral.

Porém, de acordo com Raimundo \& Zen (2010), cresce cada vez mais a preocupação do consumidor com a sanidade do alimento. E apesar de ainda ter pouquíssimo conhecimento sobre os selos de certificação dos órgãos públicos, começa a levar em consideração no 
momento da compra alguns certificados de segurança, como os promovidos por algumas redes de supermercados. Apesar disso, foi observado neste trabalho que, $18 \%$ dos alunos de Medicina Veterinária disseram não conhecer os órgãos fiscalizadores da carne suína; mesmo sendo o médico veterinário o profissional responsável por essa função. Ainda em relação à procedência do produto adquirido pelos respondentes, $68 \%$ afirmaram que só compram produtos fiscalizados pelo Serviço de Inspeção Federal (SIF) ou Serviço de Inspeção Municipal (SIM), 13,33\% não se importam se o produto que estão comprando é fiscalizado ou não e $0,67 \%$ afirmou que só compra carne clandestina.

Quanto ao rastreamento da carne, 54,36\% estudantes afirmaram que pagariam a mais por um produto que fosse comprovadamente rastreado e $45,64 \%$ não fariam o mesmo. Farias et al. (2012) afirma que a maioria dos consumidores pagaria a mais por um produto rastreável, demonstrando claramente que a população está mais consciente sobre a importância e garantia desses produtos na alimentação humana. A rastreabilidade consiste em um serviço pelo qual a carne suína será passível de acompanhamento (rastreada) desde o nascimento do leitão até sua chegada à mesa do consumidor, seja no mercado nacional ou internacional, possibilitando assim o reconhecimento da origem da carne e maior segurança, quanto a sua qualidade e inocuidade (Bezerra et al., 2007).

Quando questionados sobre por que não consumiam mais carne suína, seja in natura ou industrializada, $32,67 \%$ disseram por questões de disponibilidade, $14 \%$ pela apresentação da carne no momento da compra, $11,33 \%$ pela praticidade nos preparos dos pratos, $10,67 \%$ pela qualidade da carne que consideram insuficiente, $2,67 \%$ por falta de informação, $1,33 \%$ por acreditarem que a sanidade dos animais não é adequada e 27,33\% alegaram outros motivos, como considerarem o sabor da carne muito forte, por terem preferência por outras carnes, hábito e até mesmo por sentirem azia após o consumo. Ninguém citou o preço como limitador do preço, mesmo porque a maioria dos entrevistados, conforme supracitado consideram o preço da carne suína acessível. Diferente dos resultados encontrados por Raimundo \& Zen (2010), nos quais grande parte dos entrevistados considerou que a apresentação da carne atende suas expectativas, afirmando que o grande problema do consumo da carne ainda é o preço.

Couto \& Ferreira (2003) afirmam que, mais que o preço, o sabor e a tradição e a falta de informação sobre os benefícios da carne suína são decisivos para a ampliação do consumo. Dos entrevistados por eles, $70,3 \%$ se declaram dispostos a aumentar o consumo da carne suína caso ela fosse mais saudável. Os médicos e nutricionistas foram apontados por cerca de $75 \%$ dos entrevistados como os principais agentes formadores de opinião e, caso fosse indicado por esses profissionais, estariam dispostos a alterar seus hábitos de consumo.

Foi questionado aos alunos, o que eles consideravam que seria adequado divulgar a população para que o consumo da carne suína fosse aumentado e $46 \%$ acreditam que seriam os baixos níveis de colesterol e gordura da carne suína atualmente, $15,33 \%$ receitas e mais formas de apreciá-la que deem "água na boca", 14,67\% sabor e qualidade aprovado por nutricionistas, $13,33 \%$ tecnologias avançadas e altos controles sanitários, $8,67 \%$ os sistemas de criação dos suínos e $2 \%$ outras informações, como aumento na divulgação e marketing do produto.

De maneira geral, os resultados obtidos neste estudo confirmam que o comportamento do consumidor é caracterizado por atividades mentais e emocionais e, pode ser influenciada por fatores ambientais, pessoais e diferenças individuais, visto que, como consumidor, sofre influências psicológicas, pessoais, sociais e culturais.

\section{Conclusão}

Os alunos de Medicina Veterinária apesar de aceitarem bem o produto por seu sabor e preço acessível, ainda o rejeitam baseados em preconceitos e mitos. Porém, mostram em alguns resultados que conhecem mais sobre a suinocultura que os consumidores em geral ao apresentarem menos dúvidas sobre a produção e maior exigência de qualidade. Assim sendo, campanhas de marketing, palestras, eventos científicos e ênfase nas disciplinas dentro do currículo devem ser pensadas focando nesse público específico ao longo de todo o curso, visto que, com as informações corretas, os futuros profissionais ajudarão a disseminar as melhorias dos agronegócios neste setor, auxiliando na desmistificação da carne suína, elucidando a 
população e possivelmente, auxiliando no aumento do seu consumo.

\section{Referências}

ABPA - Associação Brasileira da Proteína Animal. Relatório Anual (2015). Disponível em: http://abpabr.com.br/files/RelatorioAnual_UBABEF_20 15_DIGITAL.pdf.

Bezerra, J. M., Cavalcante Neto, A.; Silva, L. P. G., Lui, J. F., Rodrigues, A. E. \& Martins, T. D. D. (2007). Caracterização do consumidor e do mercado da carne suína na microrregião de Campina Grande, estado da Paraíba, Ciência Animal Brasileira, 8: 485-493.

Carvalho, T. B. (2007) .Estudo da elasticidaderenda da demanda de carne bovina, suína e de frango no Brasil. Dissertação (Mestrado em Economia Aplicada). Universidade de São Paulo. Piracicaba - SP.

Cavalcante Neto, A. (2003). Caracterização, avaliação e estratégias de desmistificação dos consumidores e do mercado da carne suína no Estado da Paraíba. 102 f. Trabalho de conclusão de curso (Graduação em Zootecnia) - Centro de Ciências Agrárias, Universidade Federal da Paraíba, Areia, Paraíba.

Couto, D. L. A. \& Ferreira, A. V. (2003). Avaliação dos determinantes do consumo de carne suína no município de Patos de Minas MG. Disponível em: http://www.sober.org.br/palestra/12/04O205

Dutra Júnior, W. M., Rocha, V. R. R. A. \& Ramalho, R. P. (2004). Comportamento de consumidores de carne suína na região Metropolitana de Recife. In: Congresso Latino Americano De Suinocultura, 2, Foz do Iguaçu, Anais... Foz do Iguaçu: 533-536.

Farias, A. E. M., Brandão, P. A., Assis, D. Y. C., Costa Neto, J., Sobral, F. E. S. \& Freitas, M.R.V. (2012). Estudo socioeconômico dos consumidores de carne Suína em três municípios do sertão paraibano. Acta Veterinaria Brasilica, 6, 199-203.

FAO. (2007). Disponível em: http://www.fao.org/newsroom/en/news/2007

Kinpara, D. I. (1995). Perspectivas no consumo de carne suína no Brasil. Universidade Federal de Lavras. Caderno de Pesquisas em Administração. V.1. São Paulo.
Marchi, A. O. (2001). Consumo De Carne Suína No Brasil. Anais... 2a Conferência Internacional Virtual sobre Qualidade de Carne Suína. Concórdia, SC - Brasil.

Mattar, F. N. (1997). Novo Modelo de Estratificação Socioeconômica para Marketing e Pesquisas de Marketing. Anais..., $2^{\circ}$ SEMEAD.

Miele, M. (2011). Cadeia produtiva da carne suína no Brasil. Embrapa Suínos e Aves, Concórdia, SC. Disponível em: http://www.porkworld.com.br/artigos/post/acadeia-produtiva-da-carne-suina-no-brasil-15105.

Murata, L. S., Stein, M. R., Rezende, M. J. M. \& Almeida, M. N. (2002). Perfil do consumidor da carne suína no Distrito Federal. In: Congresso Suinocultura do Nordeste, 1, Anais.... p.105-106.

Oliveira, A. P. A. (2006). Desempenho, avaliação de carcaça e minerais nos ossos de suínos em terminação recebendo ração com fitase associada à retirada de microminerais, vitaminas e redução dos níveis de fósforo inorgânico. 63 f. Dissertação (Mestrado) Escola de Veterinária da Universidade Federal de Goiás, Goiânia.

Pedroso-de-Paiva, D. (2007). Teníase e Cisticercose: O que são? O que causam: Como prevenir?. Embrapa Suínos e Aves. Disponível em: https://www.infoteca.cnptia.embrapa.br/infote ca/bitstream/doc/438103/1/CUsersPiazzonDo cuments16487.pdf

Raimundo, L. M. \& Zen, S. (2010). Aferição do perfil do consumidor de carne suína - Estudo de caso Carrefour/Jundiaí (SP). Anais... $48^{\circ}$ congresso da Sociedade Brasileira de Economia Administração e Sociologia Rural (SOBER), Campo Grande.

Silva, J. P., Oliveira, M. F., Silva, L. P. G. (2008). Diagnóstico do consumo de "carne suína" na microrregião de Guarabira-PB, Anais..., $\mathrm{X}$ Encontro de Extensão da Universidade Federal da Paraíba.

Sheth, N. J., Mittal, B. \& Newman, I. B. (2001). Comportamento do cliente: indo além do comportamento do consumidor. 1. ed. São Paulo: Atlas.

Varga, R.M. (2015). Perfil do consumidor de carne suína do município de Florianópolis - 
SC. 34 f. Dissertação (Mestrado). Universidade Federal de Santa Catarina, Centro de Ciências Agrárias, Florianópolis.
License information: This is an open-access article distributed under the terms of the Creative Commons Attribution License, which permits unrestricted use, distribution, and reproduction in any medium, provided the original work is properly cited

Recebido em Janeiro 28, 2016

Aceito em Fevereiro 27, 2016 